to-human spread. In our outbreak, all five infants were premature (gestational age, 24-28 weeks), had low birth weight, and experienced multiple medical problems requiring indwelling catheters, parenteral nutrition, phototherapy, antibiotics, and, in three cases, steroids. These demographic characteristics are similar to those of six neonates with $M$ canis skin infection described in a previous report ${ }^{10}$ in which the source was also a nurse with skin lesions. In both of these outbreaks, $M$ canis was transmitted from person to person, which is unusual. However, all of the affected babies were premature. The skin in premature infants is a defective barrier, ${ }^{11}$ which could explain why these lowbirth-weight neonates were infected with $M$ canis carried by a nurse.

Taking the nurse off duty was the most important factor in controlling this outbreak. Other infection control measures included Contact Precautions to interfere with transmission from lesions, educating the staff about modes of transmission, and encouraging hand washing before and after patient contact. Adequate hand washing is considered the single most important means of preventing transmission of infection..$^{12}$ It is also important to clean reusable equipment. Single-use disposable items should be discarded after use and not cleaned for reuse. Investigating staffing patterns in the unit to identify the person carrying $M$ canis was unsuccessful in this episode, because many staff cross-cover each other, which is not documented in patients' charts.

Possibly, this outbreak could have been prevented if the initial dermatologist and occupational health physicians taking care of the index case had discussed communicability with this nurse, reported her to infection control, taken her off duty until her lesions healed, and had her return for follow-up care to document resolution of the lesions before allowing her to return to work.

In successfully managing this outbreak, infection control personnel, the physician dermatologist, and the veterinary dermatologist collaborated. The veterinary dermatologist confirmed that the cat was the source of $M$ canis.
Successful treatment of the nurse would not have been possible without adequate therapy for her cat. The infection control precautions had to be monitored closely until it was clear that the nurse and her cat were no longer carrying $M$ canis, and consequently she would not transmit this fungus to susceptible neonates.

From the Departments of Dermatology (Dr. Scott), Medicine (Dr. Drusin), Pediatrics (Dr. Krauss), and Public Health (Dr. Drusin), Weill Medical College of Cornell University; the Department of Epidemiology (Dr. Drusin and Ms. Ross), New York-Cornell Campus of New York Presbyterian Hospital; and the Department of Medicine (Dr. Rhodes), The Animal Medical Center, New York, New York.

This study was presented in part at the Seventh International Congress for Infectious Diseases, Hong Kong, June 1996. Dr. Rhodes currently is affiliated with the Animal Emergency and Referral Center, West Caldwell, New Jersey.

Address reprint requests to Lewis $M$. Drusin, MD, MPH, Department of Epidemiology, New York Presbyterian Hospital, New YorkCornell Campus, 525 East 68th St, New York, NY 10021.

99-OA-173. Drusin LM, Ross BG, Rhodes KH, Krauss AN, Scott $R A$. Nosocomial ringworm in a neonatal intensive care unit: a nurse and her cat. Infect Control Hosp Epidemiol 2000;21:605-607.

\section{REFERENCES}

1. Larone DH. Medically Important Fungi: A Guide to Identification. 3rd ed. Washington, DC: ASM Press; 1995

2. MacKenzie DWR. "Hairbrush diagnosis" in detection and eradication of non-fluorescent scalp ringworm. BMJ 1963;2:363-365.

3. Hay RJ. Dermatophytosis and other superficial mycoses. In: Mandell G, Bennett JE, Dolin R. eds. Principles and Practice of Infectious Diseases. 4th ed. New York, NY: Churchill Livingstone; 1995:2375-2386.

4. Jacobs AH, O'Connell BM. Tinea in tiny tots. Am J Dis Child 1986;140:1034-1038.

5. Feuerman AEJ, Grunwald M, Shvili D. Tinea capitis due to Microsporum canis in infants. Mycopathologia 1984;86:89-91.

6. Hiruma M, Kukita A. Tinea faciei caused by Microsporum canis in a newborn. Dermatologica 1988;176:130-132.

7. Jacobs AH, Jacobs PH, Mone N. Tinea facei due to Microsporum canis in an eight-day-old infant. JAMA 1972;219:1476.

8. Nelson JD. The newborn nursery. In: Bennett JV, Brachman PS, eds. Hospital Infections. 3rd ed. Boston, MA: Little Brown \& Co; 1992:441-460.

9. Mossovitch M, Mossovitch B, Alkan M. Nosocomial dermatophytosis caused by Microsporum canis in a newborn department. Infect Control 1986;7:593-595.

10. Snider R, Landers S, Levy ML. The ringworm riddle: an outbreak of Microsporum canis in the nursery. Pediatr Infect Dis J 1993;12:145-148.

11. Harpin VA, Rutter N. Barrier properties of newborn infant's skin. $J$ Pediatr 1983;102:419-425.

12. Steere AC, Mallison GF. Handwashing practices for the prevention of nosocomial infections. Ann Intern Med 1975;83:683-690

\title{
OSHA Partners With JCAHO to Promote Voluntary Protection Program
}

\section{Gina Pugliese, RN, MS Martin S. Favero, PhD}

OSHA and JCAHO recently signed an agreement to encourage healthcare institutions to participate in OSHA's Voluntary Protection Program (VPP).

Few healthcare facilities have taken advantage of the VPP, which recognizes excellence in occupational safety and health programming and exempts facilities from OSHA inspections. OSHA and JCAHO signed a 3-year partnership in 1996 to develop educational materials and promote worker safety and health. In addition, the partnership helps healthcare facilities understand how OSHA and JCAHO standards overlap. JCAHO provides specific examples in the accreditation manuals for complying with OSHA standards that also satisfy JCAHO. This partnership has been extended in the updated agreement.

FROM: OSHA Revised Voluntary Protection Program (VPP) Policies and Procedures Manual. www.OSHAgov.

JCAHO. Press release: OSHA and Joint Commission Continue Partnership to Promote Health and Safety for Health Care Workers. www.jcaho.org. 